\title{
Assessment of spatial rigidity and stability of a building when replacing reinforced concrete ribbed plates with lightweight coating
}

\author{
Valentin Babalich, Kseniya Sukhina*, Uriy Vilgelm, Vladimir Vlasov, and Kirill Sukhin \\ Volgograd State Technical University, 400006, Volgograd, Russia
}

\begin{abstract}
The tasks of restoring and ensuring the normalized parameters of the operational qualities for building structures, as well as their further safe operation in the development of capital repair and reconstruction projects, in most cases include the replacement of existing heavy coating structures with alternative lightweight ones that meet the regulated modern standards.
\end{abstract}

\section{Introduction}

When carrying out the industrial buildings and structures' reconstruction, the question of replacing the coating arises very often. This is due not only to the limited operational state of the coating structures themselves, but also to the limited bearing capacity of vertical structures (columns, walls). The most widely used alternative solution today is the replacement of heavy reinforced concrete plates with lightweight sandwich panels. However, when developing a project for a new coating of industrial buildings, it is necessary to take into account the overall spatial rigidity and stability of the entire building [1-4].

Let us consider this problem using the example of an industrial building's typical singlespan. The simplified design scheme of the structure is a spatial system consisting of bezel trusses with a span of $24 \mathrm{~m}$, columns with a pitch of $12 \mathrm{~m}$ and ribbed coating plates $12 \mathrm{~m}$ long. All structures are reinforced concrete [5-9].

Comparative assessment of spatial rigidity and stability was carried out taking into account both spatial design schemes of the building:

- design scheme with a design solution for coating the building with ribbed large-size reinforced concrete plates (option -1).

- design model with an alternative coating, profiled sheet on steel lattice girders (option 2).

In both versions of the design schemes in the figures, the enclosing wall panels are conventionally not shown [10 - 12].

\footnotetext{
*Corresponding author: zhukova_kseniya@mail.ru
} 
When calculating the system for the schemes horizontal displacement, the effect on the spatial streng _ : $\quad$ change in coating structures can be assessed [13-15].

To assess this effect, it is therefore necessary to take into account the horizontal wind force and the cranes' braking.

The static analysis of the spatial system is performed based on the loads collected above. With the following loading options:

- dead weight of system elements.

- crane $D_{\max }, D_{\min }$.

- brake $\mathrm{T}$ (in the plane of the frames).

- brake T (along graphic axes).

- wind loads on digital axes.

- wind loads along graphic axes.



Fig. 1. Finite element discretization scheme (FE).

Option-1.



Fig. 2. Finite element discretization scheme (FE).

Option-2.

Figures 1 and 2 clearly show two options for self-weight loading. 


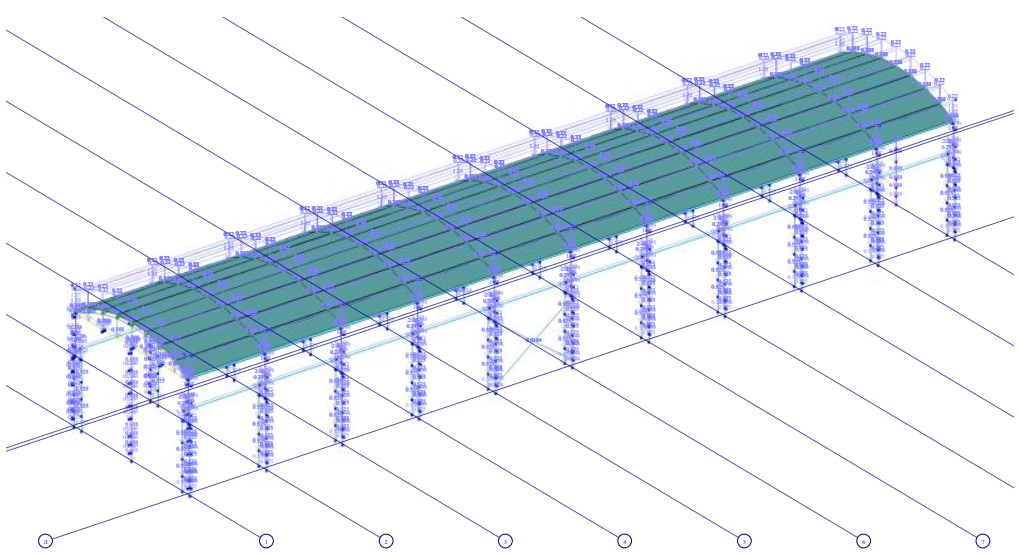

Fig. 1. The structures' own weight (according to option 1).

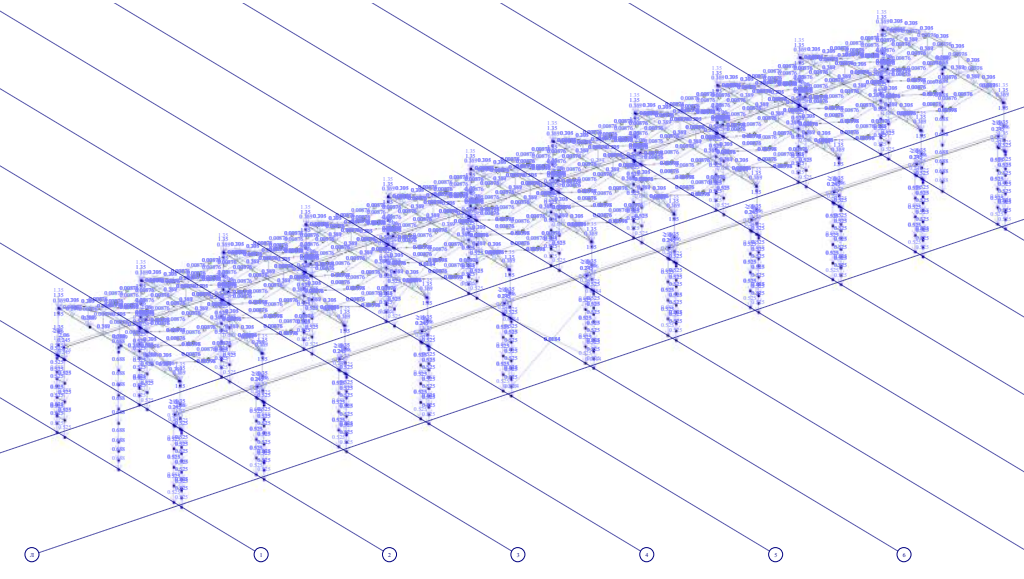

Fig. 2. The structures' own weight (according to option 2).

\section{Results obtained in studies}

Figures 3-6 show the results for the first option.

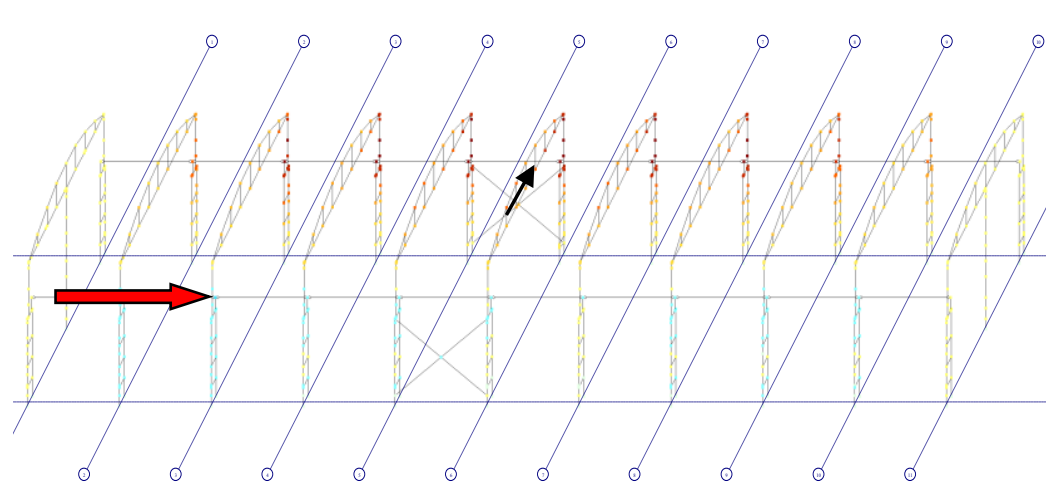

Fig. 3. Horizontal movements along digital axes (wind along graphic axes, brake along digital axes). 


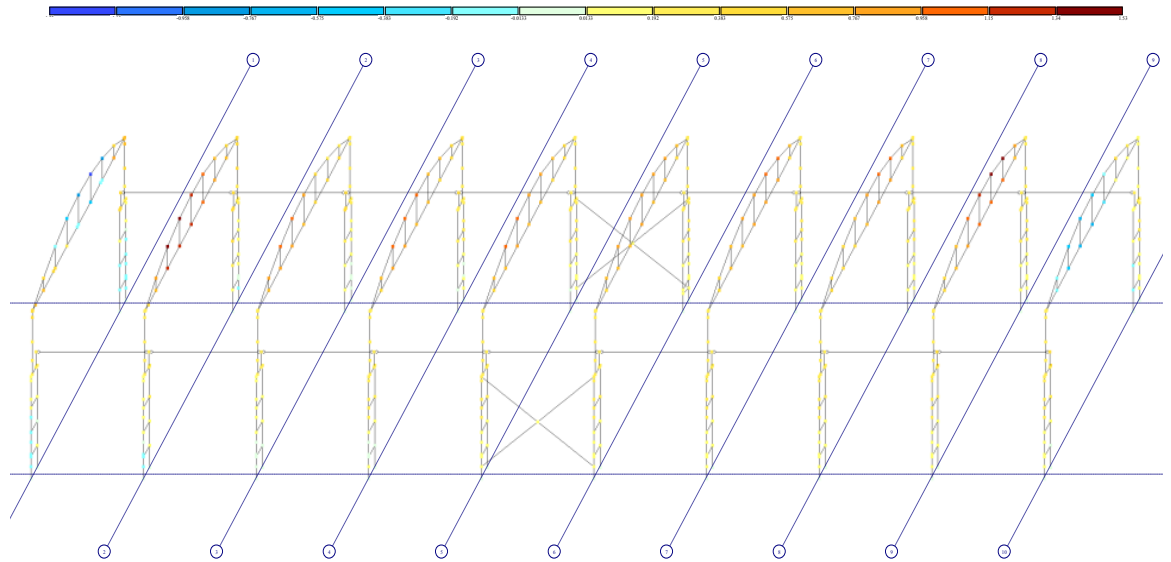

Fig. 4. Horizontal movement along graphic axes (wind along graphic axes, brake along digital axes).

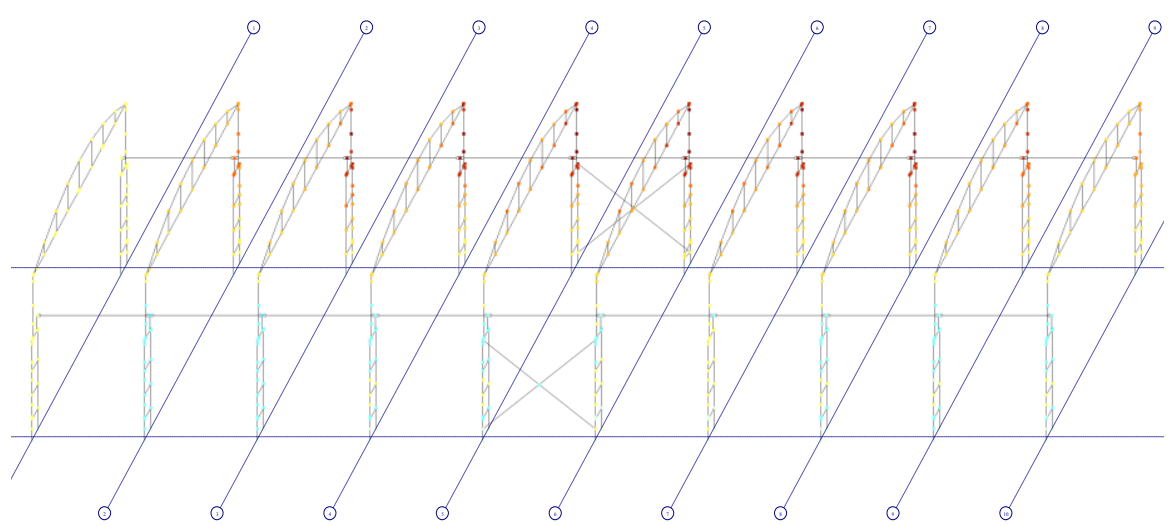

Fig. 5. Horizontal movements along digital axes (wind along graphic axes, brake along graphic axes).

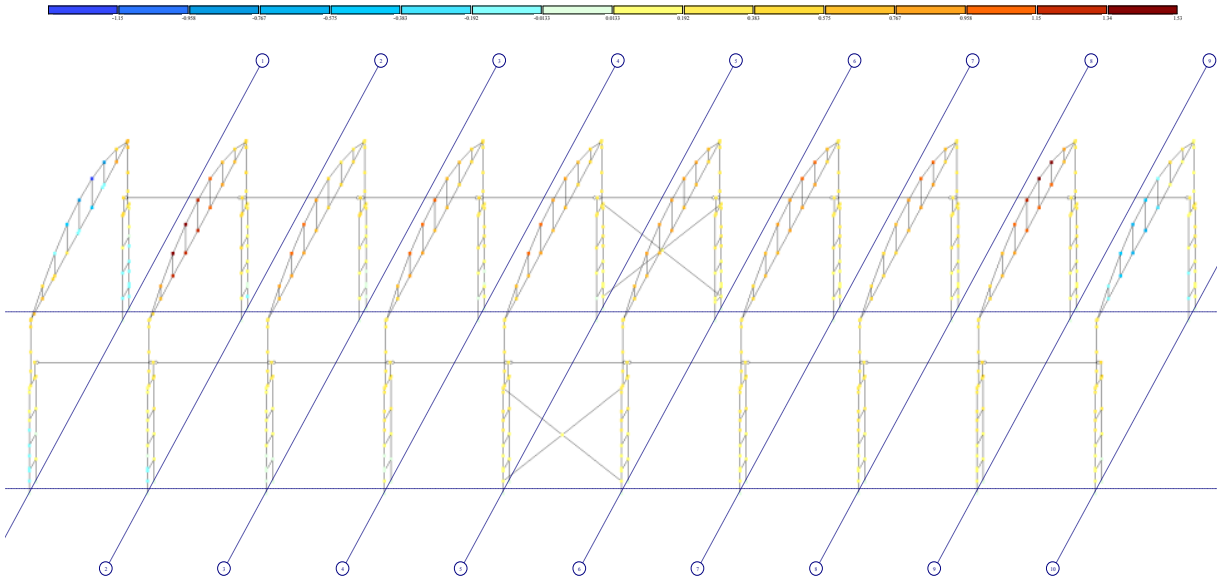

Fig. 6. Horizontal movement along graphic axes (wind along graphic axes, brake along graphic axes).

Figures 7-10 show the results for the second option. 


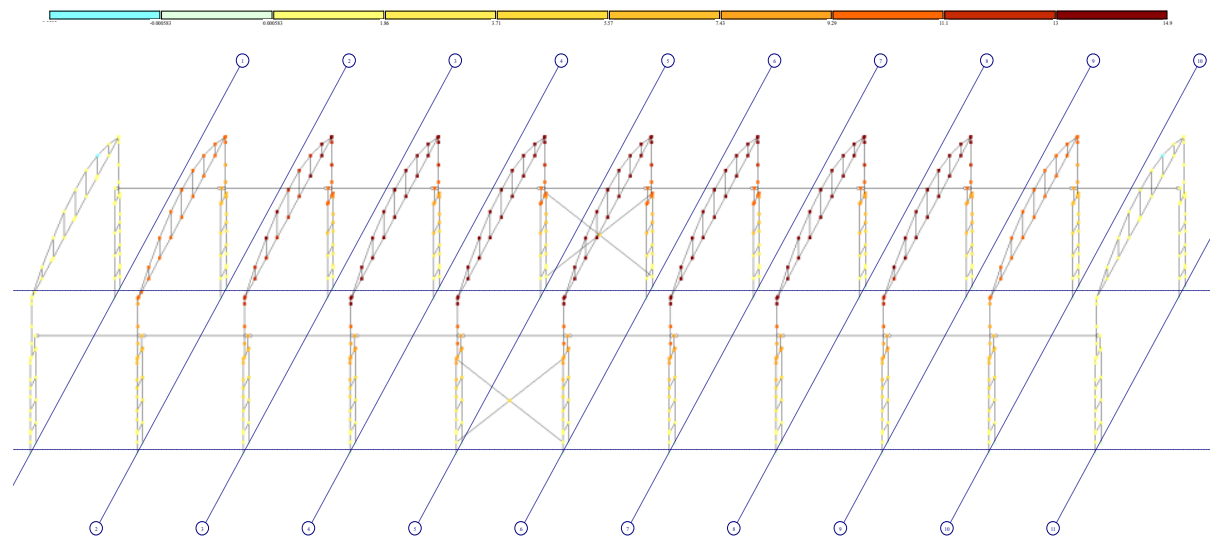

Fig. 7. Horizontal movements along digital axes (wind along graphic axes, brake along digital axes).

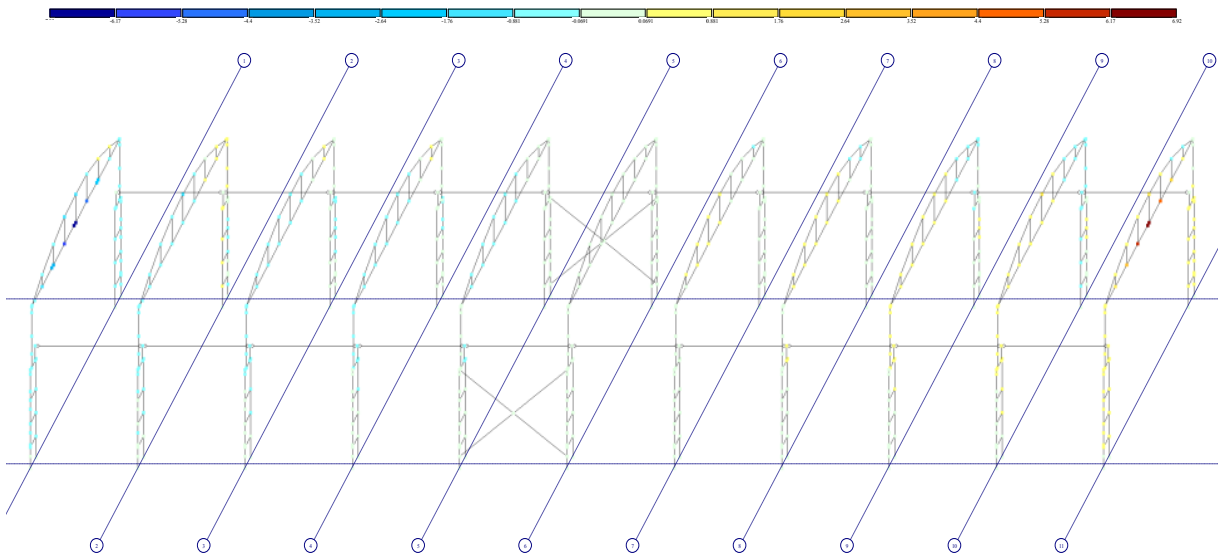

Fig. 8. Horizontal movement along graphic axes (wind along graphic axes, brake along digital axes)

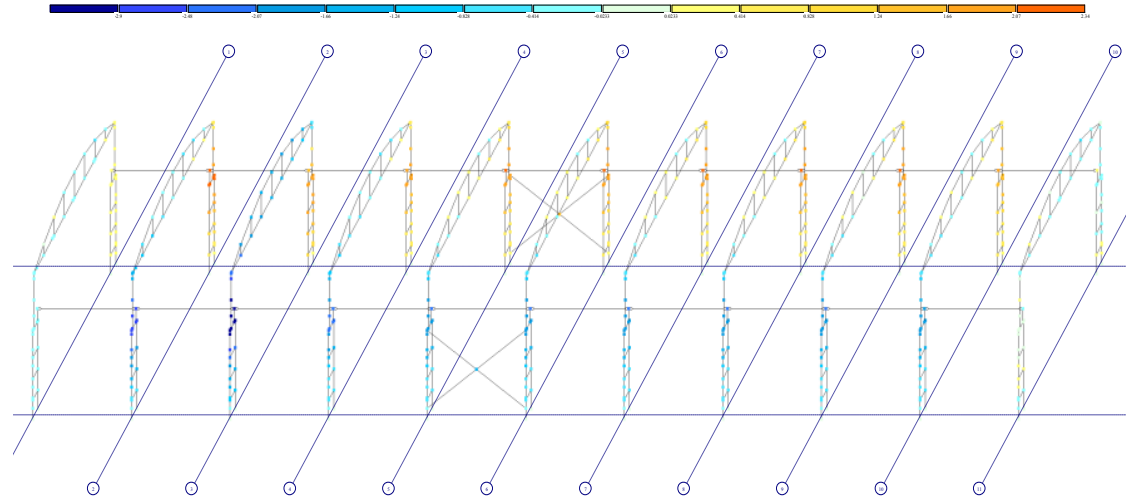

Fig. 9. Horizontal movements along digital axes (wind along graphic axes, brake along graphic axes) 


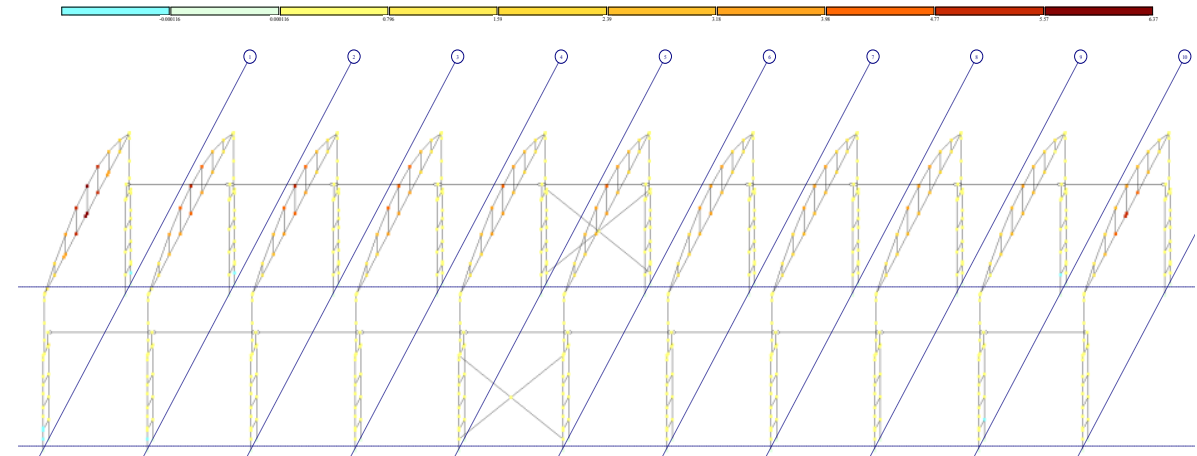

Fig. 10. Horizontal movement along graphic axes (wind along graphic axes, brake along graphic axes)

\section{Conclusion}

The main results are presented in Table 1 and only the maximum and minimum values for the construction are given.

Table 1. Main results

\begin{tabular}{|c|c|c|c|c|c|}
\hline \multicolumn{5}{|c|}{ Spatial schema } & \multicolumn{3}{c|}{ Planar diagram (axis 3) } \\
\hline \multicolumn{7}{|c|}{ Scheme 1 (design) } \\
\hline RSN1 & $\mathrm{Y}=10.5$ & $\mathrm{X}=1.53$ & RSN1 & $\mathrm{Y}=8.21$ & $\mathrm{X}=1.33$ \\
\hline RSN2 & $\mathrm{Y}=10.5$ & $\mathrm{X}=1.53$ & RSN2 & $\mathrm{Y}=5.52$ & $\mathrm{X}=1.14$ \\
\hline \multicolumn{7}{|c|}{ Scheme 2 (with binding rafters) } \\
\hline RSN1 & $\mathrm{Y}=14.9$ & $\mathrm{X}=6.92$ & RSN1 & $\mathrm{Y}=13.3$ & $\mathrm{X}=0.715$ \\
\hline RSN2 & $\mathrm{Y}=10.5$ & $\mathrm{X}=6.37$ & RSN2 & $\mathrm{Y}=13.3$ & $\mathrm{X}=0.715$ \\
\hline \multicolumn{7}{|c|}{ Scheme 3 (with binding rafters, without fencing panels) } \\
\hline RSN1 & $\mathrm{Y}=20.1$ & $\mathrm{X}=18.9$ & RSN1 & $\mathrm{Y}=20.0$ & $\mathrm{X}=3.65$ \\
\hline RSN2 & $\mathrm{Y}=20.1$ & $\mathrm{X}=18.9$ & RSN2 & $\mathrm{Y}=4.44$ & $\mathrm{X}=38.9$ \\
\hline
\end{tabular}

The results of spatial rigidity and building stability mathematical modeling gives a possibility to state that with the operation of one crane, the horizontal movements along the digital axes in both versions of the building coating differ insignificantly and practically do not condense the operational parameters, i.e., the joint work of rigid, in their plane, transverse frames, crane beams, longitudinal braking trusses, vertical braces, enclosing wall panels and coating binding rafters provide the normalized longitudinal stability of the building structures. The discrepancy in the results is due to the fact that the spatial scheme contains timber framing structures.

\section{References}

1. V.D. Raizer, Theory of Reliability in Structural Design, Journal of Applied Mechanics Reviews (USA, 2004).

2. V.D. Raizer, Reliability of Structures, Analysis and Applications (Backbone Publishing Company, New York, USA, 2009). 
3. O. Ditlevsen, H.O. Madsen, Structural reliability methods, Department of Mechanical Engineering Technical University of Denmark, 2007.

4. V.A. Pshenichkina, V.S. Babalich, K.N. Sukhina, K.A. Sukhin, Estimation of the residual life of load-bearing reinforced concrete structures of operated industrial buildings, 2017.

5. K.N. Sukhina, V.A. Pshenichkina, Probabilistic analysis of the industrial building coating structures' service life taking into account the random nature of snow load, Engineering Journal of Don, 2015. URL: ivdon.ru/ru/magazine/archive/n4y2015/3397

6. O.A. Tusnina, S.A. Pavlov, Assessment of resistance to progressive collapse of the converter shop frame, Bulletin of Civil Engineers, 2020.

7. V.M. Popov, M.G. Plyusnin, Influence of the concrete and reinforcement characteristics variability on the bearing capacity of bent reinforced concrete elements, Bulletin of Civil Engineers, 2015

8. V.D. Raizer, The theory of the structures' reliability (Scientific publication, ASV Publishing House, Moscow, 2010).

9. M.A. Bandurin, Problems of assessing the residual resource of long-term operating water supply facilities, Engineering Journal of Don, 2012. URL: ivdon.ru/ru/magazine/archive/n3y2012/891.

10. K.Yu. Lyzhnenko, A.Yu. Kubasov, D.R. Mailyan, On the issue of restoring the experimental reliability of reinforced concrete structures, Engineering Journal of Don, 2017. URL: ivdon.ru/ru/magazine/archive/n4y2017/4422.

11. S.Yu. Kalashnikov, V.A. Pshenichkina, A.A. Boyalskaya, On the issue of risk analysis of building structures, buildings and structures under extreme natural or technogenic impacts, Engineering problems of construction materials science, geotechnical and road construction. II scientific and technical conference, 2009.

12. V.A. Ostreykovsky, Reliability theory (Higher School Publishing House, Moscow, 2003).

13. V.A. Pshenichkina, S.S. Gordeev, M.A. Ivanov, The main provisions of the risk analysis method when monitoring the technical condition of buildings and structures, Low-rise construction within the framework of the National project "Affordable and comfortable housing for the Russian citizens: technologies and materials, problems and development prospects in the Volgograd region", 2009.

14. A.G. Tamrazyan, Analysis of the risk of collapse of buildings and structures from critical defects and various man-made impacts (MGSU, Moscow, 2004).

15. V.A. Pshenichkina, K.N. Sukhina, V.V. Drozdov and other, International Review of Civil Engineering 7 (9), 158-163 (2016). 